\title{
National sentinel site surveillance for antimicrobial resistance in Klebsiella pneumoniae isolates in South Africa, 2010 - 2012
}

O Perovic, ${ }^{1,2}$ MD, DTM\&H, FCPath (SA) (Microbiol), MMed (Microbiol); A Singh-Moodley, ${ }^{1,2}$ BSc, BMedSc (Hons), MMedSc, PhD;

A Dusé, ${ }^{2}$ MB BCh, DTM\&H, MSc Med, MMed, FCPath (SA) (Microbiol); C Bamford, ${ }^{3}$ MB ChB, DCH, MPhil, FCPath (SA) (Microbiol), MMed;

G Elliott, ${ }^{4} \mathrm{MB}$ ChB, FCPath (SA) (Microbiol), MMed (Microbiol), MBA;

K Swe Swe-Han, ${ }^{5}$ FCPath (SA) (Microbiol), MMed (Microbiol), DTM\&H, PDIC, MBBS;

R Kularatne, ${ }^{2}$ BSc, MB ChB, MSc Med (Microbiol), FCPath (SA) (Microbiol), DTM\&H, Dip HIV Man (SA);

W Lowman, ${ }^{2,6} \mathrm{MB}$ BCh, MMed, FCPath (SA) (Microbiol); A Whitelaw, ${ }^{7} \mathrm{MB}$ BCh, MSc, FCPath (SA) (Microbiol);

T Nana, ${ }^{2}$ MB BCh, DTM\&H, FCPath (SA) (Microbiol), MMed; J Wadula, ${ }^{2}$ MD, FCPath (SA) (Microbiol), DTM\&H, PDIC;

R Lekalakala, ${ }^{8}$ BSc, MB ChB, MMed, DTM\&H, PDIC; A Saif, ${ }^{1}$ MSc Med (Microbiol); M Fortuin De-Smidt ${ }^{1}$ BSc, BSc (Hons), MB ChB, MSc; E Marais, ${ }^{1} \mathrm{PhD}$

${ }^{1}$ Centre for Opportunistic, Tropical and Hospital Infections, National Institute for Communicable Diseases, National Health Laboratory Service, Johannesburg, South Africa

${ }^{2}$ Department of Clinical Microbiology and Infectious Diseases, School of Pathology of the University of the Witwatersrand and National Health Laboratory Service, Johannesburg, South Africa

${ }^{3}$ Division of Medical Microbiology, Department of Clinical Laboratory Sciences, Faculty of Health Sciences, University of Cape Town and National Health Laboratory Service, Groote Schuur Hospital, Cape Town, South Africa

${ }^{4}$ InterSystems, Sandton, Johannesburg, South Africa

${ }^{5}$ Department of Medical Microbiology, Inkosi Albert Luthuli Hospital, Durban, South Africa, and Microbiology Department, National Health Laboratory Service, University of KwaZulu-Natal, Durban

${ }^{6}$ Wits University Donald Gordon Medical Centre, Parktown, Johannesburg, South Africa

${ }^{7}$ Division of Medical Microbiology, Faculty of Medicine and Health Sciences, Stellenbosch University and National Health Laboratory Service, Tygerberg Hospital, Cape Town, South Africa

${ }^{8}$ Department of Medical Microbiology, University of Pretoria and Tshwane Academic Division, National Health Laboratory Service, Pretoria, South Africa

Correspondingauthor: O Perovic (olgap@nicd.ac.za,olga.perovic@nhls.ac.za)

Background. The increasing rates of antimicrobial resistance observed in the nosocomial pathogen Klebsiella pneumoniae are of major public health concern worldwide.

Objectives. To describe the antibiotic susceptibility profiles of $K$. pneumoniae isolates from bacteraemic patients submitted by sentinel laboratories in five regions of South Africa from mid-2010 to mid-2012. Molecular methods were used to detect the most commonly found extended-spectrum beta-lactamase (ESBL) and carbapenemase resistance genes.

Methods. Thirteen academic centres serving the public healthcare sector in Gauteng, KwaZulu-Natal, Free State, Limpopo and Western Cape provinces submitted K. pneumoniae isolates from patients with bloodstream infections. Vitek 2 and MicroScan instruments were used for organism identification and susceptibility testing. Multiplex polymerase chain reactions (PCRs) were used to detect $b l a_{C T X-M}, b l a_{\text {SHV }}$ and $b l a_{\mathrm{TEM}}$ genes in a proportion of the ESBL isolates. All isolates exhibiting reduced susceptibility to carbapenems were PCR tested for $b l a_{\mathrm{KPC}}$ and $b l a_{\mathrm{NDM}-1}$ resistance genes.

Results. Overall, $68.3 \%$ of the 2774 isolates were ESBL-positive, showing resistance to cefotaxime, ceftazidime and cefepime. Furthermore, $46.5 \%$ of all isolates were resistant to ciprofloxacin and $33.1 \%$ to piperacillin-tazobactam. The major ESBL genes were abundantly present in the sample analysed. Most isolates (95.5\%) were susceptible to the carbapenems tested, and no isolates were positive for $b l a_{\mathrm{KPC}}$ or $b l a_{\mathrm{NDM}-1 \text {. }}$ There was a trend towards a decrease in susceptibility to most antibiotics.

Conclusion. The high proportion of ESBL-producing K. pneumoniae isolates observed, and the prevalence of ESBL genes, are of great concern. Our findings represent a baseline for further surveillance in SA, and can be used for policy and treatment decisions.

S Afr Med J 2014;104(8):563-568. DOI:10.7196/SAMJ.7617

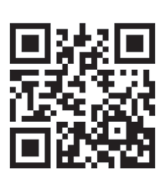

The increasing prevalence of serious hospitaland community-acquired infections is of great concern, with patients dying as a result of emerging antimicrobial resistance. Antibiotic-resistant organisms are widespread globally, both in developed and developing countries. ${ }^{[1]}$ These organisms are a major threat to public health, reduce the effectiveness of empiric antimicrobial treatment options, and increase morbidity, mortality and healthcare expenditure. A national surveillance system for antimicrobial resistance is essential to establish a baseline of the extent of the problem, to follow trends of resistance, and to form the basis for recommendations of appropriate antimicrobial use to clinicians and other healthcare providers. A 
national system also controls for differences in case selection, data management and demographic descriptions of regional populations. To meet this need, a national laboratory-based antimicrobial resistance surveillance system for nosocomial pathogens was established in 2010, which included Klebsiella pneumoniae as a sentinel organism by which to monitor resistance.

$K$. pneumoniae is an important nosocomial pathogen, with the highest prevalence of resistance to third- and fourthgeneration cephalosporins among the Enterobacteriaceae. The spread of class A or group 2 be extended-spectrum betalactamases (ESBLs) in Enterobacteriaceae is of public health concern. The most frequently detected and clinically important ESBLs belong to the TEM, SHV, and CTX-M families, and $K$. pneumoniae commonly produces all three groups of enzymes. ${ }^{[2]}$ In the past decade, CTX-M enzymes have emerged as the most prevalent type. There are more than 100 different types, which can be broadly divided into five groups based on their amino-acid identities: CTX-M1, CTXM2, CTX-M8, СТX-M9 and CTX-M25. Enzymes are characterised by epidemiological differences, and some have even been shown to spread beyond the hospital environment into the community. ${ }^{[2]}$ Of further public health concern are the recent emergence of K. pneumoniae strains capable of producing carbapenem-hydrolysing enzymes and the apparent ease of spread of resistance mechanisms by mobile genetic elements. ${ }^{[2]}$

There are few published reports on national antimicrobial resistance rates of K. pneumoniae in South Africa (SA), with data primarily emanating from the private sector, ${ }^{[3]}$ regional studies with limited numbers of local isolates ${ }^{[1]}$ or certain clinical settings. ${ }^{[4]}$ To date, molecular data on ESBL K. pneumoniae in SA are based on detailed studies of small populations. Essack et al. ${ }^{[5]}$ examined $b l a_{\mathrm{SHV}}$ and $b l a_{\mathrm{TEM}}$ genes in 25 isolates, and found a high degree of diversity in terms of plasmids present, genes detected and the combination of genes within isolates. In a study of ESBL $K$. pneumoniae from seven countries in $2003, b l a_{\text {TEM-10, }}, b l a_{\text {TEM-12' }}$ $b l a_{\mathrm{TEM}-63}$, various $b l a_{\mathrm{SHV}-2}$ and $b l a_{\mathrm{SHV}-5}$ types, $b l a_{\mathrm{CTX}-\mathrm{M} 2}$ and $b l a_{\mathrm{CTX}-\mathrm{M} 3}$ genes were detected in $27 \mathrm{SA}$ isolates. ${ }^{[6]} \mathrm{A}$ more recent study on 53 ESBL clinical pathogens from Pretoria detected $b l a_{\mathrm{TEM}}, \quad b l a_{\mathrm{SHV}}$ and $b l a_{\mathrm{CTX}-\mathrm{M}-1}$ genes, although the contribution of the 31 $K$. pneumoniae isolates in this group was not specified. ${ }^{[7]}$ This diversity in enzyme production and the prolific nature of $K$. pneumoniae as a nosocomial pathogen highlight the need for further investigation into the genes responsible for these enzymes in the SA setting.

In this study, we determined the antibiotic susceptibility profiles of $K$. pneumoniae isolates from bacteraemic patients with positive blood cultures from sentinel sites representing five SA regions. We used national laboratory-based surveillance data to characterise the third- and fourthgeneration cephalosporin-resistant and carbapenem-resistant phenotypes and genotypes of K. pneumoniae from 2010 to 2012.

\section{Methods}

\section{Patient selection}

Thirteen academic centres serving the public healthcare sector in SA were included, and participation was voluntary. The sites represented regions in Gauteng, KwaZuluNatal, Free State, Limpopo and Western Cape provinces. Isolates of $K$. pneumoniae from patients with bloodstream infections were submitted, with a 3-week exclusion thereafter to avoid duplicate isolates of the same organism.

\section{Phenotypic methods}

$K$. pneumoniae isolates were submitted on Dorset transport media. Organism identification was confirmed using the Vitek 2 GN card (Biomerieux, France). Susceptibility testing and determination of ESBL phenotype was performed on the MicroScan Walkaway (Siemens Healthcare Diagnostics, USA), using NM37 panels. Categorical results and susceptibility profile of each antimicrobial agent tested were based on 2012 Clinical Laboratory Standards Institute (CLSI) interpretative criteria, ${ }^{[8]}$ the European Committee on Antimicrobial Susceptibility Testing guidelines ${ }^{[9]}$ and/ or the MicroScan recommendations. The $\mathrm{MIC}_{50}$ and $\mathrm{MIC}_{90}$ (minimum inhibitory concentrations needed to inhibit the growth of $50 \%$ and $90 \%$ of organisms, respectively) were determined. The Agresti-Coull interval method was used to calculate confidence intervals, and a $\chi^{2}$ test was performed to analyse trends in antibiotic susceptibility. A $p$-value of $<0.05$ was deemed statistically significant.

\section{Genotypic methods}

Two hundred and seventy ESBLproducing isolates were randomly selected (approximately $14 \%$ per region) and screened for the presence of ESBL genes. DNA was extracted from half a loop ( 2 $\mathrm{mm}$ in diameter) of bacterial culture. This was resuspended in $400 \mu \mathrm{l}$ trisethylenediaminetetraacetic acid buffer (pH 8.0), vortexed briefly, heated at $95^{\circ} \mathrm{C}$ for 25 minutes and pelleted by centrifugation. The supernatant was aliquoted and stored at $-70^{\circ} \mathrm{C}$ for further use.

The LightCycler 480 instrument (Roche Applied Science, Germany) and LightCycler 480 Probes Master kit (Roche Diagnostics, USA) were used for real-time polymerase chain reaction (PCR). The $b l a_{\mathrm{TEM}}$ and $b l a_{\mathrm{SHV}}$ genes were amplified by multiplex real-time PCR using the primers shown in Table 1. The primers were selected for specificity by GenBank comparisons and PCR products from control strains were sequenced. The limit of detection was determined to be 750 colony-forming units ( $\mathrm{cfu}) / \mathrm{ml}$ for $b l a_{\text {TEM }}$ and $4000 \mathrm{cfu} / \mathrm{ml}$ for $b l a_{\mathrm{SHV}}$. The reaction conditions were $0.5 \mu \mathrm{M}$ primers, $0.2 \mu \mathrm{M}$ probes, denaturation for $95^{\circ} \mathrm{C}$ for 5 minutes, and then 45 cycles of $95^{\circ} \mathrm{C}$ for 10 seconds, $55^{\circ} \mathrm{C}$ for 30 seconds and $72^{\circ} \mathrm{C}$ for 1 second. The $b l a_{\text {Стх-м }}$ PCR was a multiplex assay targeting bla ${ }_{\text {CTX-M }}$ groups M1 and M2-9 using primer and probe sequences as described previously. ${ }^{[10]}$ Detection of $b l a_{\mathrm{NDM}-1}$ and $b l a_{\mathrm{KPC}}$ genes was performed on isolates with reduced susceptibility to carbapenems as described previously. ${ }^{[11]}$ Reduced susceptibility to carbapenems was defined according to the CLSI guidelines of 2012. ${ }^{[8]}$ Strains from the

\begin{tabular}{ll} 
Table 1. Primer and probe sequences for $\boldsymbol{b l a}_{\mathrm{TEM}}$ and $\boldsymbol{b l a}_{\mathbf{S H V}_{\mathbf{v}}}$ gene detection \\
\hline SHV Forward Primer & 5'-CAG CAG GAT CTG GTG GAC TAC T-3' \\
SHV Reverse Primer & 5'-GTC AAG GCG GGT GAC GTT-3' \\
SHV A Primer & 5'-AAG GCG GGT GAC GTT GTC-3' \\
SHV S Primer & 5'-CCG GTC AGC GAA AAA CAC-3' \\
SHV Probe & 5'-Cy5-TCT GGC GCA AAA AGG CAG TCA-BBQ-3' \\
TEM Forward Primer & 5'-AAG TTC TGC TAT GTG GTG CGG TA-3' \\
TEM Reverse Primer & 5'-TGT TAT CAC TCA TGG TTA TGG CAG C-3' \\
TEM A Primer & 5'-GTA AGA TGC TTT TCT GTG ACT GGT GA-3' \\
TEM S Primer & 5'-AGT TCT GCT ATG TGG TGC GGT ATT A-3' \\
TEM Probe & 5'-FAM-TGC GGC GAC CGA GTT GCT CTT-BBQ-3'
\end{tabular}


American Type Culture Collection (ATCC) or the National Culture Collection Laboratory of the National Institute for Communicable Diseases were used as positive controls.

\section{Results}

A total of 2774 discrete K. pneumoniae isolates were received and included in the antimicrobial susceptibility testing over the 3 -year period. The majority of isolates demonstrated an ESBL phenotype (68.3\%) with marked resistance to third- and fourthgeneration cephalosporins. The distribution of isolates according to province, and ESBL rates, are shown in Table 2. A breakdown of susceptibility by agent for the 3-year period is presented in Fig. 1.

Reduced carbapenem susceptibility was noted in only 124 (4.5\%) of isolates (Table 2). The carbapenemase genes $b l a_{\mathrm{NDM}-1}$ and $b l a_{\mathrm{KPC}}$

\begin{tabular}{|c|c|c|c|}
\hline Province & $\begin{array}{l}\text { Isolates } \\
\text { submitted } 2010 \text { - } \\
2012, N\end{array}$ & $\begin{array}{l}\text { ESBL-positive } \\
\text { isolates } \\
2010-2012, n(\%)\end{array}$ & $\begin{array}{l}\text { Reduced carbapenem } \\
\text { susceptibility, } n(\%)\end{array}$ \\
\hline Gauteng & 1737 & 1207 (69.5) & $75(4.3)$ \\
\hline Western Cape & 620 & $414(66.8)$ & $25(4.0)$ \\
\hline KwaZulu-Natal & 268 & $203(75.7)$ & $15(5.6)$ \\
\hline Free State & 134 & $59(44.0)$ & $7(5.2)$ \\
\hline Limpopo & 15 & $12(80.0)$ & $2(13.3)$ \\
\hline Totals & 2774 & $1895(68.3)$ & $124(4.5)$ \\
\hline
\end{tabular}

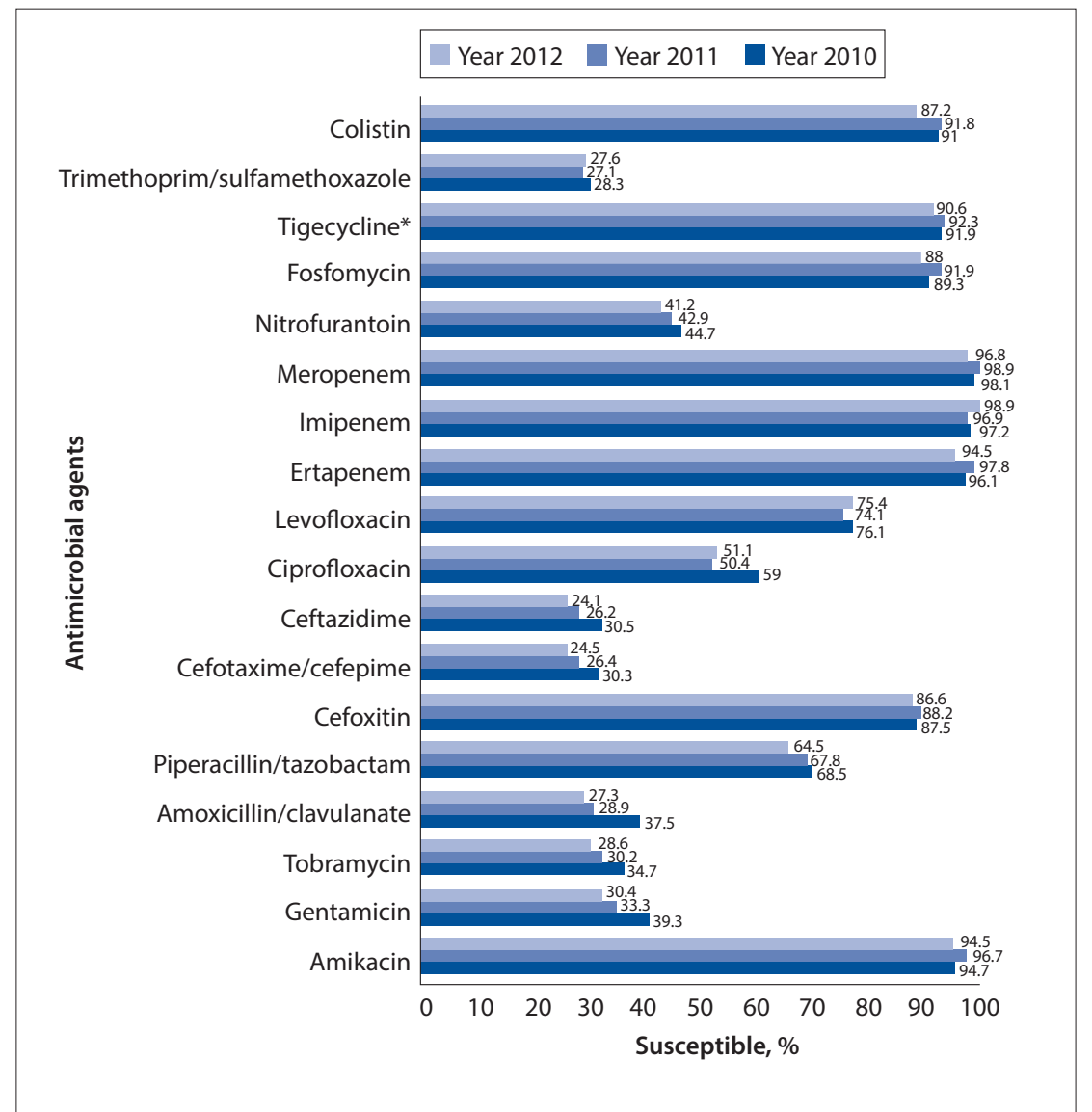

Fig. 1. Percentage susceptibility to antimicrobial agents, 2010 - 2012. Confidence intervals were a maximum of $\pm 2 \%$ for all antibiotics for each year. Susceptibility percentages for cefotaxime and cefepime were identical. $\left({ }^{*}\right.$ European Committee on Antimicrobial Susceptibility Testing guidelines. $\left.{ }^{(9)}\right)$ were not detected in any of the 124 isolates and the presence of other carbapenemaseproducing genes was not investigated.

Susceptibility to aminoglycosides over the 3-year period was variable, with $95.3 \%$ susceptible to amikacin but only $31.1 \%$ and $31.3 \%$ susceptible to tobramycin and gentamicin, respectively (Fig. 1). Susceptibility to levofloxacin (75.2\%) was higher than to ciprofloxacin (53.5\%). Sixty-seven (66.9\%) per cent of all isolates were susceptible to piperacillin-tazobactam $\left(\mathrm{MIC}_{50}=8 \mu \mathrm{g} / \mathrm{ml}\right)$ for the 3 years, and susceptibility to cefoxitin was high at $87.4 \%$ (Table 3).

Trend analysis was performed on the isolates, comparing the susceptibility rates between 2010, 2011 and 2012 (Table 4). Small but statistically significant declines in susceptibility rates were noted for many antibiotics, including amoxicillin/ clavulanate, tobramycin, gentamicin, ciprofloxacin, ceftazidime and cefotaxime.

Molecular characterisation was performed on 270 ESBL-positive isolates. All phenotypically ESBL-positive isolates were confirmed to possess one or more of the $b l a_{\text {СТX-M }}, b l a_{\text {SHV }}$ and $b l a_{\text {TEM }}$ genes, with $93.0 \%$ of the isolates tested expressing more than one resistance gene (Fig. 2).

\section{Discussion}

Gauteng contributed the majority of isolates in the study (62.6\%), probably because it is the most populous province with the largest academic centres. The high percentage of bacteraemic K. pneumoniae that were resistant to third-generation cephalosporins (68.3\%) is of serious public health concern. Rates of resistance in a 2006 study from SA private laboratories showed 52\% resistance to cefuroxime, $46 \%$ to ceftriaxone and $44 \%$ to cefepime. ${ }^{[3]}$ A study of resistance at seven public sector hospitals between 2010 and 2012 reported an overall level of ESBL detection of $65 \%{ }^{[12]}$ Our study shows a similar rate $(68.3 \%)$ of resistance to extended-spectrum cephalosporins. The difference between the private and public sectors may indicate a dramatic increase in development of resistance in the interim, and/or a difference in sampling and resistance patterns between these sectors. Also, because they are referral centres, the academic centres that submitted isolates in this study potentially contributed a disproportionate number of patients who were more likely to harbour ESBL isolates. Globally, reports show a trend towards an increase in resistance of $K$. pneumoniae to third-generation cephalosporins. ${ }^{[13]}$ While rates of resistance are low in some countries, 
Table 3. Antibiotic $\mathrm{MIC}_{50}, \mathrm{MIC}_{90}$ and breakpoints for $2774 \mathrm{~K}$. pneumoniae isolates

\begin{tabular}{|c|c|c|c|c|c|c|c|c|}
\hline \multirow[b]{2}{*}{ Antibiotics } & \multicolumn{2}{|c|}{2010} & \multicolumn{2}{|c|}{2011} & \multicolumn{2}{|c|}{2012} & \multicolumn{2}{|c|}{$\begin{array}{c}\text { MIC interpretive } \\
\text { breakpoints }(\mu \mathrm{g} / \mathrm{ml})^{*}\end{array}$} \\
\hline & $\mathrm{MIC}_{50}$ & $\mathrm{MIC}_{90}$ & $\mathrm{MIC}_{50}$ & $\mathrm{MIC}_{90}$ & $\mathrm{MIC}_{50}$ & $\mathrm{MIC}_{90}$ & $\mathrm{~S}$ & $\mathbf{R}$ \\
\hline Amikacin & $\leq 8$ & 16 & $\leq 8$ & 16 & $\leq 8$ & 16 & $\leq 16$ & $\geq 64$ \\
\hline Gentamicin & $>8$ & $>8$ & $>8$ & $>8$ & $>8$ & $>8$ & $\leq 4$ & $\geq 16$ \\
\hline Tobramycin & $>8$ & $>8$ & $>8$ & $>8$ & $>8$ & $>8$ & $\leq 4$ & $\geq 16$ \\
\hline $\begin{array}{l}\text { Amoxicillin/ } \\
\text { clavulanate }\end{array}$ & $16 / 8$ & $>16 / 8$ & $16 / 8$ & $>16 / 8$ & $16 / 8$ & $>16 / 8$ & $\leq 8 / 4$ & $\geq 32 / 16$ \\
\hline $\begin{array}{l}\text { Piperacillin/ } \\
\text { tazobactam }\end{array}$ & $\leq 8$ & $>64$ & $\leq 8$ & $>64$ & $\leq 8$ & $>64$ & $\leq 16 / 4$ & $\geq 128 / 4$ \\
\hline Cefoxitin & $\leq 8$ & 16 & $\leq 8$ & 16 & $\leq 8$ & 16 & $\leq 8$ & $\geq 32$ \\
\hline Cefotaxime & $>32$ & $>32$ & $>32$ & $>32$ & $>32$ & $>32$ & $\leq 1$ & $\geq 4$ \\
\hline Ceftazidime & 16 & $>16$ & 16 & $>16$ & $>16$ & $>16$ & $\leq 4$ & $\geq 16$ \\
\hline Cefepime & $>16$ & $>16$ & $>16$ & $>16$ & $>16$ & $>16$ & $\leq 8$ & $\geq 32$ \\
\hline Ciprofloxacin & $\leq 0.5$ & $>2$ & $\leq 0.5$ & $>2$ & 1 & $>2$ & $\leq 1$ & $\geq 4$ \\
\hline Levofloxacin & $\leq 1$ & $>4$ & $\leq 1$ & $>4$ & $\leq 1$ & $>4$ & $\leq 2$ & $\geq 8$ \\
\hline Ertapenem & $\leq 0.5$ & $\leq 0.5$ & $\leq 0.5$ & $\leq 0.5$ & $\leq 0.5$ & $\leq 0.5$ & $\leq 0.5$ & $\geq 2$ \\
\hline Imipenem & $\leq 2$ & $\leq 2$ & $\leq 2$ & $\leq 2$ & $\leq 2$ & $\leq 2$ & $\leq 1$ & $\geq 4$ \\
\hline Meropenem & $\leq 1$ & $\leq 1$ & $\leq 1$ & $\leq 1$ & $\leq 1$ & $\leq 1$ & $\leq 1$ & $\geq 4$ \\
\hline Nitrofurantoin & 64 & $>64$ & 64 & $>64$ & 64 & $>64$ & $\leq 32$ & $\geq 128$ \\
\hline Fosfomycin & $\leq 32$ & $>32$ & $\leq 32$ & $>32$ & $\leq 32$ & $>32$ & $\leq 64$ & $\geq 256$ \\
\hline Tigecycline $^{\dagger}$ & $\leq 1$ & $\leq 1$ & $\leq 1$ & $\leq 1$ & $\leq 1$ & $\leq 1$ & $\leq 1$ & $>2$ \\
\hline $\begin{array}{l}\text { Trimethoprim/ } \\
\text { sulfamethoxazole }\end{array}$ & $>4 / 76$ & $>4 / 76$ & $>4 / 76$ & $>4 / 76$ & $>4 / 76$ & $>4 / 76$ & $\leq 2 / 38$ & $\geq 4 / 76$ \\
\hline Colistin $^{\dagger}$ & $\leq 2$ & $\leq 2$ & $\leq 2$ & $\leq 2$ & $\leq 2$ & 4 & $\leq 2$ & $\geq 2$ \\
\hline
\end{tabular}

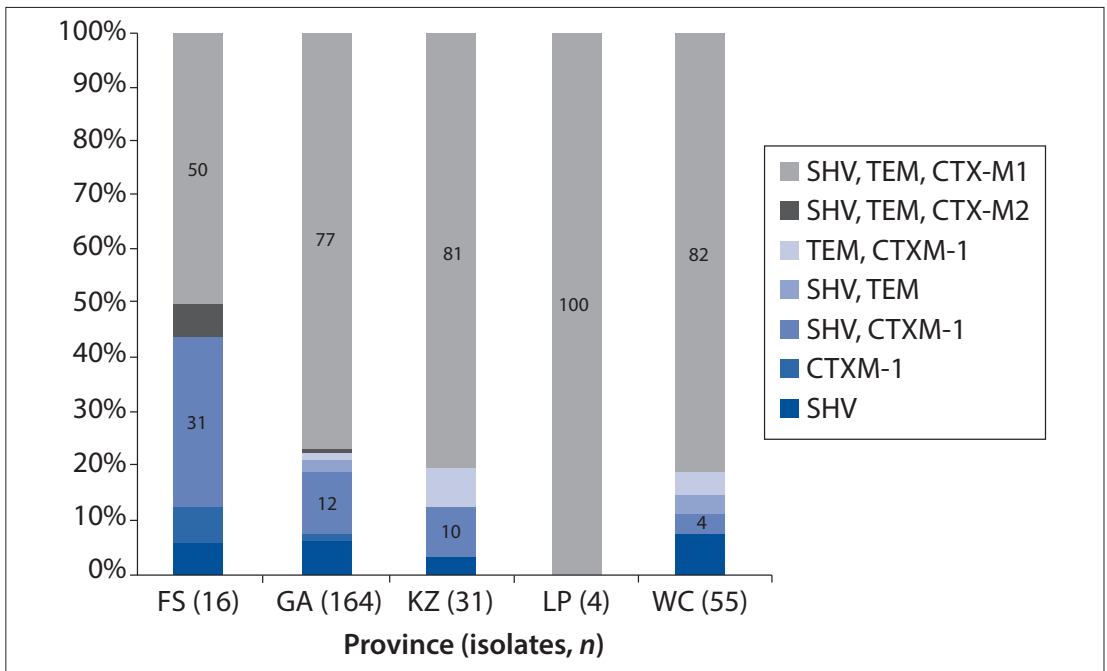

Fig. 2. Distribution of ESBL genes as percentages in 270 isolates tested. Percentages of the most frequent combinations are shown as data labels. (ESBL = extended-spectrum beta-lactamase; FS = Free State; GA = Gauteng; $K Z=$ KwaZulu-Natal; $L P=$ Limpopo; $W C=$ Western Cape.)

e.g. $11.5 \%$ in 2010 in the USA, ${ }^{[13]}$ higher rates have been observed in other regions. ${ }^{[14]}$ three major groups of ESBL genes throughout five regions of SA. The almost identical susceptibility pattern to cefotaxime, ceftazidime and cefepime suggests that there are multiple copies of several ESBL genes in the sample, which is supported by the genotypic results. A limitation of the study is that the genotypic data represent only $14 \%$ of $K$. pneumoniae isolates from selected academic or referral laboratories, and may not be fully representative at a national level. The phenotypic data support the genotypic data, however, being fairly representative of all isolates sampled in this survey. These results are also a first indication of the extensive prevalence of $b l a_{\mathrm{SHV}}, b l a_{\mathrm{TEM}}$ and $b l a_{\mathrm{CTX}-\mathrm{M}}$ genes in geographically distinct regions of SA.

Susceptibility to carbapenems was high, with only $4.5 \%$ of isolates showing reduced susceptibility. However, carbapenem-resistant Enterobacteriaceae have been described in $S A,{ }^{[15]}$ and levels of carbapenem resistance need to be monitored closely. It must also be noted that the breakpoints for ertapenem 
have since been revised by the CLSI. ${ }^{[8]} \mathrm{A}$ limitation of this study is that we only tested for $b l a_{\mathrm{NDM}-1}$ and $b l a_{\mathrm{KPC}}$ genes and did not investigate for other potential mechanisms of carbapenem resistance.

For piperacillin-tazobactam, the $\mathrm{MIC}_{50}$ was within the susceptible breakpoint while the $\mathrm{MIC}_{90}$ was above the resistant breakpoint. Overall susceptibility was $66.9 \%$, and piperacillin-tazobactam may therefore be a potentially useful agent for treatment. However, there is still debate concerning the use of piperacillintazobactam to treat infections with ESBLproducing Enterobacteriaceae. There is some evidence that outcomes may be worse if the piperacillin-tazobactam MIC is $8-16$ $\mathrm{mg} / \mathrm{l}$, with suggestions that if piperacillintazobactam is used to treat organisms with these MICs, prolonged infusions or more frequent dosing may be needed. ${ }^{[16]}$

The $87.4 \%$ susceptibility to cefoxitin suggests that plasmid-mediated AmpC enzymes are not particularly prevalent in this sample. The disparity in ciprofloxacin and levofloxacin resistance $(21.7 \%$ difference) is intriguing and although we do not have genotypic data to support it, it may represent an increase in quinolone resistance mechanisms (e.g. plasmid-mediated mechanisms; enzymatic modification) other than the conventional target site mutations, where one would expect cross-resistance ${ }^{[17]}$ as $61.5 \%$ ESBL of $K$. pneumoniae isolates were resistant to ciprofloxacin.

Among all aminoglycosides, amikacin exhibited the best activity, although this must be interpreted with caution as the stipulated breakpoints are high considering that this is a concentration-dependent agent. The $\mathrm{MIC}_{50}$ and $\mathrm{MIC}_{90}$ of $8 \mu \mathrm{g} / \mathrm{ml}$ and $16 \mu \mathrm{g} / \mathrm{ml}$, respectively, indicate that for many isolates the probability of achieving adequate serum levels is quite low.

Overall, the $\mathrm{MIC}_{50}$ and $\mathrm{MIC}_{90}$ to most agents have not changed over the 3-year period, although the ability to detect smaller differences may have been limited by the methodological system employed for susceptibility testing. The one exception was colistin, for which a significant increase in $\mathrm{MIC}_{90}$ was noted in $2012(p=0.001)$ (Table $4)$. This is alarming, as colistin represents the mainstay of the treatment of most of our extensively drug-resistant Gram-negative pathogens (including carbapenem-resistant K. pneumoniae). ${ }^{[18]}$ Trends in susceptibility showed a significant decrease over the study period for most antimicrobial agents, with a few exceptions, e.g. piperacillin-tazobactam, levofloxacin and tigecycline.

Table 4. Statistical significance of antibiotic susceptibility rates for K. pneumoniae, 2010 - 2012

\begin{tabular}{|c|c|c|c|}
\hline \multirow[b]{2}{*}{ Antibiotics } & \multicolumn{3}{|c|}{$p$-value ${ }^{\star}$} \\
\hline & 2010 v. 2011 & 2011 v. 2012 & 2010 v. 2012 \\
\hline Amikacin & 0.041 & 0.012 & 0.908 \\
\hline Gentamicin & 0.013 & 0.145 & $<0.001$ \\
\hline Tobramycin & 0.056 & 0.428 & 0.015 \\
\hline Amoxicillin/clavulanate & $<0.001$ & 0.397 & $<0.001$ \\
\hline Piperacillin/tazobactam & 0.713 & 0.105 & 0.103 \\
\hline Cefepime & 0.087 & 0.295 & 0.014 \\
\hline Cefoxitin & 0.668 & 0.252 & 0.616 \\
\hline Ceftazidime & 0.058 & 0.272 & 0.007 \\
\hline Ciprofloxacin & 0.001 & 0.749 & 0.003 \\
\hline Levofloxacin & 0.37 & 0.481 & 0.771 \\
\hline Ertapenem & 0.05 & $<0.001$ & 0.166 \\
\hline Imipenem & 0.774 & 0.002 & 0.016 \\
\hline Meropenem & 0.14 & $<0.001$ & 0.141 \\
\hline Nitrofurantoin & 0.488 & 0.42 & 0.194 \\
\hline Fosfomycin & 0.076 & 0.003 & 0.468 \\
\hline Tigecycline & 0.736 & 0.15 & 0.417 \\
\hline Trimethroprim/sulfamethoxazole & 0.602 & 0.768 & 0.796 \\
\hline Colistin & 0.591 & $<0.001$ & 0.028 \\
\hline
\end{tabular}

A limitation of this study was that comprehensive patient demographic details were unavailable, and it was not possible to determine accurate trends in patient age, ward and gender. This information will be obtained in future surveys, allowing for more detailed analyses of antimicrobial resistance patterns, and how they change over time.

These surveillance results should be used together with hospital-specific data as tools in antimicrobial stewardship programmes and for the development of empiric therapy guidelines for healthcare-associated infections. Ongoing antimicrobial resistance surveillance, performed in a systematic and standardised manner, could be used as a tool to monitor the effectiveness of antimicrobial stewardship programmes that have been implemented in various centres across the country. Moreover, it provides a foundation for the systematic surveillance of important hospital pathogens that could be expanded and enhanced over time.

\section{Conclusion}

SA appears to have a relatively high percentage of ESBL-producing K. pneumoniae isolates in comparison with other geographical regions, which is of great concern, and a significant increase in ertapenem resistance over the surveillance period. This study presents the antibiotic resistance patterns of invasive $K$. pneumoniae isolates and gives an indication of the prevalence of resistance genes. Our findings provide important baseline data for further site-specific analysis of $K$. pneumoniae isolates, as well as a platform for enhanced surveillance of $K$. pneumoniae antimicrobial resistance in the country. Additionally, when analysed in conjunction with patient demographic and clinical details these data are important for the development of empiric therapy guidelines for management of sepsis in SA healthcare institutions.

Acknowledgements. This study was supported by GERMS-SA (the Group for Enteric, Respiratory and Meningeal disease Surveillance in South Africa). We thank Ms Serisha Naicker, Mr Elias Khomane, Mrs Zazi Molebatsi and Mrs Marshagne Smith for assistance with the laboratory work and Ms Penny Crowther for assistance with our database.

References

1. Ashley EA, Lubell Y, White NJ, et al. Antimicrobial susceptibility of bacterial isolates from community acquired infections in SubSaharan Africa and Asian low and middle income countries. Trop Med Int Health 2011; 16 (9):1167-1179. [http://dx.doi org/10.1111/j.1365-3156.2011.02822.x 
2. Gutkind GO, Di Conza J, Power P, et al. $\beta$-lactamase-mediated resistance: A biochemical, epidemiological and genetic overview. Curr Pharm Des 2013; 19(2):164-208. [http://dx.do

3. Brink A, Moolman J, da Silva MC, et al. Antimicrobial susceptibility profile of selected bacteraemic pathogens from private institutions in South Africa. S Afr Med J 2007;97(4):273-279.

4. Brink AJ, Botha RF, Poswa X, et al. Antimicrobial susceptibility of Gram-negative pathogens isolated from patients with complicated intra-abdominal infections in South African hospitals (SMART Study 2004-2009): Impact of the new carbapenem breakpoints. Surg Infect (Larchmt) 2012; 13(1):43-49. [http:// dx.doi org/10.1089/sur 2011.074

5. Essack SY, Hall LM, Pillay DG, McFadyen ML, Livermore DM. Complexity and diversity of Klebsiella pneumoniae strains with extended-spectrum beta-lactamases isolated in 1994 and 1996 at a teaching hospital in Durban, South Africa. Antimicrob Agents Chemother 2001; 45(1):88-95. [http://dx.doi. org/10.1128/AAC.45.1.88-95.2001]

6. Paterson DL, Hujer KM, Hujer AM et al. Extended-spectrum beta-lactamases in Klebsiella pneumonia loodstream isolates from seven countries: Dominance and widespread prevalence of SHV- an CTX-M-type beta-lactamases. Antimicrob Agents Chemother 2003;47(11):3554-3560. [http://dx.doi. org/10.1128/AAC.47.11.3554-3560.2003]

7. Ehlers MM, Veldsman C, Makgotho EP, et al. Detection of $b l_{\mathrm{SH}} b l_{\mathrm{TEM}}$ and $b l_{\mathrm{CTX}-\mathrm{M}}$ antibiotic resistance genes in randomly selected bacterial pathogens from the Steve Biko Academic Hospital. FEMS Immuno Med Microbiol 2009; 56(3):191-196. [http://dx.doi.org/ 10.1111/j.1574-695X.2009.00564.x]

8. Performance Standards for Antimicrobial Susceptibility Testing: Twenty-Second Informationa Supplement. Clinical and Laboratory Standards Institute. M100-S22 (Vol. 32, No. 1): 2012:45-61.

. The European Committee on Antimicrobial Susceptibility Testing (EUCAST). Breakpoint tables for interpretation of MICs and zone diameters. http://www.eucast.org (accessed 3 July 2014).

10. Birkett CI, Ludlam HA, Woodford N, et al. Real-time TaqMan PCR for rapid detection and typing of genes encoding CTX-M extended-spectrum beta-lactamases. J Med Microbiol 2007;56(1):52-55. [http:// dx.doi.org/10.1099/jmm.0.46909-0]
11. Centers for Disease Control and Prevention. Multiplex real-time PCR detection of Klebsiella pneumoniae carbapenemase (KPC) and New Delhi metallo- $\beta$-lactamase (NDM-1) genes. 2012. http://www.cdc.gov/ $\mathrm{HAI} / \mathrm{settings} / \mathrm{lab} / \mathrm{kpc}$-ndml-lab-protocol.htm (accessed 3 July 2014)

12. Bamford C, Bonorchis K, Ryan A, et al. Antimicrobial susceptibility patterns of selected bacteraemic isolates from South African public sector hospitals, 2010. South African Journal of Infectious Diseases

13. Braykov NP, Eber MR, Klein EY, et al. Trends in resistance to carbapenems and third-generation cephalosporins among clinical isolates of Klebsiella pneumoniae in the United States, 1999-2010. Infect Control Hosp Epidemiol 2013;34(3):259-268. [http://dx.doi.org/10.1086/669523]

14. Mendes RE, Mendoza M, Banga Singh KK, et al. Regional resistance surveillance program results fo twelve Asia-Pacific nations (2011). Antimicrob Agents Chemother 2013;57(11):5721-5726. [http:// dx.doi.org/10.1128/AAC.01121-13]

15. Lowman W, Sriruttan C, Nana T, et al. NDM-1 has arrived: First report of a carbapenem resistance mechanism in South Africa. S Afr Med J 2011;101(12):873-875

16. Nguyen HM, Shier KL, Graber CJ. Determining a clinical framework for use of cefepime and $\beta$-lactam $/ \beta$ lactamase inhibitors in the treatment of infections caused by extended-spectrum- $\beta$-lactamase-producing Enterobacteriaceae. J Antimicrob Chemother 2014;69(4):871-880. [http://dx.doi.org/10.1093/jacl dkt450]

17. Robicsek A, Strahilevitz J, Jacoby GA, et al. Fluoroquinolone-modifying enzyme: A new adaptation of a common aminoglycoside acetyltransferase. Nat Med 2006; 12(1):83-88. [http://dx.doi.org/10.1038/ nm1347]

18. Visser Kift E, Maartens G, Bamford C. Systematic review of the evidence for rational dosing of colistin. S Afr Med J 2014; 104(3):183-186. [http://dx.doi.org/10.7196/SAMJ.7011]

Accepted 11 April 2014 